\title{
Humor: goles y autogoles de Roberto Bolaño
}

\author{
Cecilia García-Huidobro Mac Auliffe $\left(^{*}\right)$
}

Al ser una sociedad futbolizada, muchos consideran a este deporte como la épica de estos tiempos. Una especie de epopeya con guardalíneas. Roberto Bolaño no escapó a su encantamiento, claro que a su manera, no podía ser de otro modo.

"Mi experiencia como jugador de fútbol nunca fue del todo comprendida ni por los espectadores ni por mis compañeros de equipo. A mí siempre me pareció más interesante marcar un autogol que un gol. Un gol salvo si uno se llama Pelé o Didí o Garrincha, es algo eminentemente vulgar y muy descortés con el arquero contrario, a quien no conoces y que no te ha hecho nada, mientras que un autogol es un gesto de independencia. Aclaras ante tus compañeros y ante el público, que tu juego es otro"1.

Algunos vieron en esta afirmación una provocación, otros una declaración de principios. Y por qué no ambas. ¿Quién dijo que no se puede hacer una declaración de principios con mordacidad? Sobre todo si quien la hace es Bolaño, un jugador nato, para quien "la literatura es un ejercicio aburrido y antinatural, entonces, si no te lo tomas como un juego, o también como un juego, puede llegar a convertirse en un suplicio" ${ }^{\prime 2}$. He aquí su descarnada e ingeniosa descripción de lo que en buenas cuentas es la poética bolañesca. Según el crítico Christopher Domínguez

"pocos como él sacaron tanto provecho de la diáspora sudamericana de los años setenta, convirtiendo los dolores ideológicos en profecías literarias, encontrando en el terror su esencia metafísica, demostrando que la prosa puede y debe ser, al mismo tiempo, un juguete literario y una apuesta por la gravedad" ${ }^{\prime 3}$.

Apuestas que Bolaño construyó desde una república independiente -ajena a capillas y corrillos literarios, políticos o académicos-, sobre la base del humor que alguna vez

(*) Licenciada en Periodismo y Pedagogía en Castellano. Magíster en Literatura de la Pontificia Universidad Católica de Chile. Decana de la Facultad de Comunicación y Letras de la Universidad Diego Portales.

Correo electrónico: cecilia.ghuidobro@udp.cl.

${ }^{1}$ Bolaño por sí mismo (entrevistas escogidas), Ediciones Universidad Diego Portales, Santiago, 2006, p.125.

${ }^{2} \mathrm{Op}$, cit. , p. 92.

${ }^{3}$ http: / / www.letraslibres.com/interna.php?sec $=6 \&$ art $=6829$ 
calificó como "una de las cosas más importantes del mundo. Pienso que, en jerarquía, por encima del humor sólo está el amor. En ese sentido, coincido con los surrealistas"4.

Pero no se trata de insertarlo en el discurso. Es más bien una mirada, una respiración, una forma de vida. En una de sus primeras entrevistas se le preguntó por su permanente actitud provocativa con el mundo literario. Respondió:

"Cuando escribo -insisto en esto a riesgo de parecer pedante (que por otra parte es probable que lo sea)- lo único que me interesa es la escritura, es decir la forma, el ritmo, el argumento. Me río de algunas actitudes, de algunas personas, de ciertos quehaceres y de ciertas gravedades porque simplemente ante tamaños despropósitos, ante tamaños pavos hinchados, no queda más remedio que reírse. Toda literatura, de alguna manera, es política. Quiero decir, es reflexión política y es planificación política. El primer postulado alude a la realidad, a esa pesadilla o a ese sueño bienhechor que llamamos realidad y que concluye, en ambos casos, con la muerte y con la abolición no sólo de la literatura sino también del tiempo. El segundo postulado alude a las briznas que perviven, a la continuidad, a la sensatez, aunque, por supuesto, sepamos que en términos humanos, en una medida humana, la continuidad es una entelequia y la sensatez solo una frágil verja que nos impide desbarrancarnos en el abismo" ${ }^{\prime 5}$.

Es ahí donde Bolaño procura instalar su escritura, en esa frontera última que bordea el abismo, con una prosa lúdica y reflexiva a la vez. Y es que vivir intentando equilibrarse en esos inseguros bordes, no hay otra forma de soportarlo que con humor. Aliviana la carga y conlleva la necesidad de complicidad. El humor, como lo definió Bergson, un clásico en esta materia, es una forma social de comunicación. En otras palabras se requiere de ciertos códigos compartidos. Las condiciones hilarantes que aparecen en ciertas fisuras de la realidad al mostrar contradicciones, vueltas de tuercas, situaciones inesperadas, demandan la participación de otro. Esto cobra todavía mayor relevancia en una sociedad que ha exacerbado el individualismo. El humor postmoderno, al decir de Alejandro Romero,

"colaboraría en el mantenimiento del vínculo social, siempre en cuestión desde que la comunidad dejó paso a la asociación, poniendo en contacto experiencias individuales, estructurando lo masificado y comunicando entre sí átomos dispersos en una celebración lúdica de su idiosincrasia" ${ }^{\prime}$.

El humor fue, pues, para Roberto Bolaño una estética y una ética.

Este rasgo -presente en toda su obra-, aparece desde sus primeros escritos. Veamos, por ejemplo, su segunda novela Literatura nazi en América, publicada en 1996. Algo así como tomar una parte por el todo, lo que si se trata de Bolaño no es una arbitrariedad, al menos no una arbitrariedad mayor. Él mismo señaló que así concebía su obra. "Un todo no sólo estilístico, sino también un todo argumental: los personajes

\footnotetext{
${ }^{4}$ Op. cit., p. 117.

${ }^{5}$ Carmen Boullosa, Roberto Bolaño: la literatura como tauromaquia. Cecilia Manzoni (editora), Ediciones Corregidor, Buenos Aires, 2002. En Bolaño por sí mismo, Op, cit., p. 119.

${ }^{6}$ Alejandro Romero R., El humor en la teoría sociológica postmoderna, p. 342, http://digibug.ugr.es/bitstream/10481 /1918/1/17548779.pdf.
} 
están dialogando continuamente entre ellos y están apareciendo y desapareciendo"7.

En cualquier caso, esta obra temprana es considerada por la crítica como una obra de gran madurez junto a Estrella distante publicada el mismo año, a diferencia de la primera novela La pista de hielo que se asemeja a la publicada póstumamente el 2010, Tercer Reich, donde los rasgos propios de su imaginario y estilo están en forma más incipiente. De hecho en esta última no aparecen prácticamente elementos sarcásticos.

Desde el mismo título -Literatura Nazi en América- se aprecia cierta intención de bromear con ciertos formatos. Más de alguien en una librería habrá pensado que se trataba de un diccionario de autores o un manual sobre el tema, muy especialmente si la edición en cuestión es la que Seix Barral hizo en 2005 y que reproduce una secuencia de 4 fotografías de Hitler. Con tal mal gusto, cualquiera se confunde. La contratapa en cambio, juega con la situación al decir que se trata de

"una antología vagamente enciclopédica de la literatura filo-nazi producida en América desde 1930 a 2010, un contexto cultural que, a diferencia de Europa, no tiene conciencia de lo que es y donde se cae con frecuencia en la desmesura".

Obviamente no se trata de una parodia inventada por él. De inmediato se vienen a la mente algunos casos pero muy especialmente, Historia universal de la infamia de Borges, cuyos rastros de complicidad hay que buscarlos en el sentido del humor, el juego, constantes burlas y la mezcla de datos reales y ficticios que contribuye a crear, como subraya José Miguel Oviedo "una sensación de verosimilitud en lo disparatado"s.

Además, la estructura del volumen deja la sensación que dicha parodia cobra vida propia y comienza ramificarse. Mientras las falsas biografías enciclopédicas son breves, las últimas son equivalentes a un cuento, como si sus personajes hubieran empezado a proliferar en forma amenazante. De hecho así ocurre pues esta última entrada, "Ramírez Hoffman" es también el punto de partida de Estrella Distante. Una obra como un sendero de relatos que se bifurcan... El volumen termina con una verdadera provocación a través de una advertencia. "Cuídate, Bolaño, dijo finalmente y se marchó" (p. 199).

$\mathrm{Su}$ permanente sarcasmo para con el mundo literario cobra forma en la segunda parte llamada "Epílogo para monstruos", con secciones como "Algunos personajes", "Algunas editoriales, revistas y lugares" y "Algunos libros". Una cita para calibrar dicho tono: "Duquesa de Bahamontes, Córdoba, 1883-Madrid, 1957. Duquesa y cordobesa. Y punto. Sus amantes (platónicos) se contaron por cientos. Problemas de orina y anorgasmia. En la vejez, buena jardinera".

Es un humor carente de retórica. Más bien parece construido con la levedad que Italo Calvino reclamó para la literatura del siglo XXI en sus Seis propuestas para un nuevo milenio. Sería posible citar numerosos pasajes divertidos. La "biografía" del escritor de ciencia ficción de

\footnotetext{
${ }^{7}$ Marcelo Soto, Revista Qué Pasa, Santiago, 20 de julio de 1998.

${ }^{8}$ José Miguel Oviedo, "La Literatura nazi de América de Roberto Bolaño", Revista Letras Libres, noviembre de 2005.
} 
gran éxito Zach Sodenstern, por ejemplo, nacido en Los Ángeles en 1962 y fallecido en la misma ciudad el año $2021^{\prime}$, es hilarante de principio a fin, incluida la descripción el perro del protagonista, Flip, "un pastor alemán mutante y vagabundo, con poderes telepáticos y tendencias nazis"... Hacia el final se habla de unos apuntes de una novela encontrada en el computador del autor luego de su muerte, donde se espera la llegada de un nuevo Mesías asociado al Cuarto Reich y que podría ser el hijo de Flip, el perro.

Para los distraídos que pudieran confundir el sentido del título y contenido de la novela, el epígrafe de Augusto Monterroso debería alertarlos: "Cuando el río es lento y se cuenta con una buena bicicleta o caballo sí es posible bañarse dos (y hasta tres, de acuerdo con las necesidades higiénicas de cada quien) veces en el río". Tal parece que el lector puede bañarse varias veces en estas páginas puesto que su significado está precisamente en ese contrapunto entre apariencia y realidad. Dice Bolaño:

"En Literatura Nazi en América yo cojo el mundo de la ultraderecha, pero muchas veces, en realidad, de lo que hablo ahí es de la izquierda. Cojo la imagen más fácil de ser caricaturizada para hablar de otra cosa. Cuando hablo de los escritores nazis de América, en realidad estoy hablando del mundo a veces heroico y muchas más veces canalla de la literatura en general"10.

Como otras obras de Bolaño, Literatura nazi en América, carece de pesadez aunque se sitúa en los intersticios de lo siniestro. En sus páginas pone en práctica lo que consideraba la esencia de la literatura, "meter la cabeza en lo oscuro", pero con los desplazamientos propios de la ironía. De allí que uno de sus traductores, el poeta y catedrático australiano Chris Andrews lo considera un escritor elegiaco pero sin provocar una atmósfera lastimera.

"La historia le dio su gran tema: las desdichas de su generación perdida, la de los que se hicieron adultos, a veces muy bruscamente, en los años setenta. (...) Las vidas que nos relata Bolaño, imaginarias o no, están llenas de esperanzas y proyectos fallidos. A él, como a Samuel Beckett, el éxito le parece pobre y monótono, comparado con la casi infinita variedad del fracaso". Y sin embargo, leer a Bolaño no es deprimente, muy por el contrario (...) Los buenos no suelen triunfar en la obra de Bolaño, pero aun derrotados comunican alegría simplemente por su existencia y su modo de ser: valiente sin necesidad de heroísmo, generoso sin el prurito de complacer a todos, ajeno al sadismo como al masoquismo ${ }^{11}$.

Este concepto, Bolaño lo acompaña con la construcción de un personaje de sí mismo que puso en marcha incluso antes de publicar. Sus primeras armas se observan muy bien en su adolescencia con revista Infra, "Revista Menstrual del movimiento Infrarrealista" publicada en México en los años setenta. Allí sienta las bases de un juego en el que pone buena parte de sus fichas en la ironía como un camino para reflejar la tensión entre apariencia y realidad. Luego encontró en la entrevista, un campo fértil para la irreverencia y la provocación. La mejor tribuna para tomarle el pelo a medio mundo. Una mira telescópica con la que dispara a los poderes fácticos y sus vicios (incluidos los

\footnotetext{
${ }^{9}$ La fecha parece un error pues la contratapa habla de una antología que abarca 1930 a 2010, aunque puede ser parte del juego.

${ }^{10}$ Mihály Dés, Roberto Bolaño (1953-2003), Jornadas ICCI Casa América de Cataluña, Barcelona, 2005.

${ }^{11}$ C. Andrews, "Roberto Bolaño: elegía y alegría", Revista Mensaje, Santiago de Chile, noviembre de 2003.
} 
del mundo cultural y literario o muy especialmente mundo cultural y literario mejor dicho). El humor entonces utilizado como camuflaje y arma en una batalla (guerrilla debí decir) sin cuartel y de antemano destinada al fracaso como solía subrayar Bolaño.

Parecida actitud reveló en sus discursos, que siempre fueron un intento por hablar de la literatura de una forma también literaria. En una clara deuda con los antidiscursos de Nicanor Parra, Bolaño emplea la ironía en su reflexión y juega con el formato hasta desactivar todas sus claves convencionales y transfórmalos en otro espacio de creación para hablar de la creación.

Famoso por el desconcierto que produjo fue su discurso con ocasión de la entrega del premio Rómulo Gallegos en 1998, premio que se considera un emblema de su consagración definitiva y que concluye con estas palabras:

"Me siento como Pinocho". O "Sevilla me mata" del 2003 que su avanzada enfermedad no le permitió leer (moriría un par de meses después): "Espero que nadie tome a mal mis anteriores palabras. Era broma... A estas alturas de mi vida ya no quiero más amigos gratuitos. Estoy aquí porque quiero enseñaros a ser hombres. No es verdad. Era broma. En realidad me muero de envidia cuando os veo. No sólo a vosotros sino a todos los jóvenes escritores latinoamericanos. Tenéis futuro, os lo puedo asegurar. Pero no es verdad. Era broma..." 12

De manera cantisflesca, Bolaño dice y se desdice aun cuando cada una de sus expresiones encierra un significado. No se trata del sinsentido anglosajón, sino de un cuestionamiento frente a una realidad que claramente puede engendrar su contrario. Si existe una complejidad estriba precisamente en la simultaneidad con que puede ocurrir algo atroz y algo hermoso.

Desentrañar entonces la presencia del mal y la violencia que conlleva, es uno de los tópicos más representativos de su escritura. ¿Cuándo y, sobre todo cómo puede la imaginación literaria hacerse cargo de la violencia y el horror históricos?

Para Bolaño el verso de Baudelaire -'En desiertos de tedio, un oasis de horror' es una lúcida expresión de la enfermedad del hombre moderno.

"Para salir del aburrimiento, para escapar del punto muerto, lo único que tenemos a mano, y no tan a mano, también en esto hay que esforzarse, es el horror, es decir el mal. O vivimos como zombis, como esclavos alimentados con soma, o nos convertimos en esclavizadores, en seres malignos ${ }^{\prime \prime 13}$.

Como si se hubiera hecho cargo de la pregunta de Hanna Arendt respecto de cómo enfrentar la terrible banalidad del mal, buena parte de la obra de Roberto Bolaño se ocupó precisamente de lo que significa cierta convivencia con el mal que termina por convertirlo en algo trivial y cotidiano. Algo en lo que cualquiera podría verse involucrado ya sea como víctima o como victimario. “Sabe un hombre, siempre, lo

\footnotetext{
${ }^{12}$ Roberto Bolaño, “Sevilla me mata", En Entreparéntesis, Editorial Anagrama, Barcelona 2004, p. 313.

${ }^{13}$ Roberto Bolaño, "Literatura+ enfermedad= enfermedad”, En El gaucho insufrible, Editorial Anagrama, Barcelona, 2003, p 151.
} 
que está bien y lo que está mal?"14, se pregunta el protagonista de su libro Nocturno de Chile. Frente a una disyuntiva tan dramática, el humor se transforma en un recurso importante, aunque no necesariamente divertido. "El humor -dice Bolaño- no siempre entra en el proceso de escribir como algo placentero para el escritor. Mucho del humor que aparece en Los detectives salvajes es producto de una rajadura, y no es precisamente un humor placentero. Es un humor negro y, en ocasiones, doloroso"15. Diferente es desenmascarar el mal que banalizarlo aunque a ratos puedan confundirse.

Una literatura humorística es para Bolaño también una particular deuda de las letras latinoamericanas, como lo expresó en un breve artículo bajó el título de "El humor en el rellano" donde menciona a sus grandes inspiradores en este registro: Bioy y Borges, Cortázar, algo de Puig, Parra por supuesto. Y no mucho más en las letras de nuestro continente ${ }^{16}$.

El valor del fracaso es, para quienes no somos hinchas del fútbol, lo más admirable de ese deporte. "Siempre hay lugar, individual y colectivamente hablando, para los perdedores" 17 . Y no olvidemos que en su infancia, Bolaño, fue un pésimo jugador, según contó en su Discurso de Caracas. Incluso relata que por las noches le daba vueltas a su

"lamentable condición de futbolista y fue entonces cuando tuve el primer atisbo consciente de mi condición de dislexia. Yo chuteaba con la izquierda pero escribía con la derecha (...) Y ahí estaba el problema. Por ejemplo, cuando el entrenador decía: pásale al de tu derecha, Bolaño, yo no sabía a qué lado tenía que pasar la pelota. E incluso a veces, jugando por la banda izquierda, ante la voz desgañitada de mi entrenador yo me paraba y tenía que pensar: izquierda-derecha. Derecha era el campo de fútbol, izquierda era sacarla fuera, hacia los pocos espectadores, niños como yo, o hacia los potreros miserables de Quilpué, o de Cauquenes, o de la provincia de Bío-Bío".

Acaso fue en esas canchas terrosas de su infancia donde Bolaño tomó la determinación de hacer su propio juego y subvertir las reglas e incluso ironizar con ellas sobre todo con aquellas que procuraban crear tontos útiles, como dijera César Luis Menotti al referirse a la política deportiva de la dictadura militar argentina ${ }^{18}$.

Quizás, después de todo, le debemos al fútbol haber tenido un escritor de la categoría de Bolaño. Autor, por cierto, de goles y autogoles inolvidables.

\footnotetext{
${ }^{14}$ Roberto Bolaño, Nocturno de Chile, Editorial Anagrama, Barcelona, sexta edición, p. 113.

${ }^{15}$ Bolaño por sí mismo (entrevistas escogidas), Ediciones Universidad Diego Portales, Santiago, 2006, p. 93.

${ }^{16}$ Roberto Bolaño, "El humor en el rellano", En Entreparéntesis, Editorial Anagrama, Barcelona 2004, pp. 224 - 225.

${ }^{17}$ Pedro Gandolfo, El Mercurio, 12 de mayo, Cuerpo A, p. 2.

${ }^{18}$ Política con las que el Gobierno Militar argentino cosechó, sin embargo, el título en el Campeonato Mundial de 1978.
} 